University of Colombo Review (Series III),

Vol. 1, No. 1, 2020

\title{
The COVID-19 Pandemic and Complexity Science: A Convergence of Earth Systems, Virus Species, the Urbanocene and Physical Hyper-Connectivity
}

\author{
Saroj Jayasinghe \\ Chair Professor of Medicine, Faculty of Medicine, University of Colombo
}

\begin{abstract}
The pandemic of The COVID-19 caused by the Severe Acute Respiratory Syndrome Coronavirus 2 (SARS-CoV-2) has changed global systems, at least temporarily. There is good evidence that the virus originated in wild animals around the Chinese city of Wuhan and spread to other areas and became a pandemic affecting almost all countries in the globe. This article explores the pandemic through a systems science approach and views it from the perspective of the SARS-CoV-2 virus. It proposes a novel conceptualization where the pandemic emerges from four converging systems: the earth systems, the urbanocene (i.e. the urbanization processes and spaces that have become the main living space of the human species), the system of mobile humans and objects, and the virus with its potential to infect.

Loss of biodiversity is an important change to the earth system that promotes the emergence of zoonotic infections. The infective virus and its transmissibility are other factors promoting the epidemic. The urbanocene has resulted in high densities of populations that facilitate the spread of epidemics. Finally, the hyper-connectivity of human species and physical objects it has produced (e.g. planes and cargo) and their movement across thousands of miles often from city to city has promoted widespread dissemination of the virus. As the underlying systems evolved in parallel, a critical point was reached which resulted in synergies that led to the emergence of the COVID-19 pandemic.
\end{abstract}

\section{KEY WORDS:}

The COVID pandemic, complexity science, earth systems, the urbanocene, hyper-connectivity

Suggested Citation: Jayasinghe, S. (2020). The COVID-19 Pandemic and Complexity Science: A Convergence of Earth Systems, Virus Species, the Urbanocene and Physical Hyper-Connectivity. University of Colombo Review (New Series III). 1 (1). $05-15$

(c) 2020 The Authors. This work is licenced under a Creative Commons Attribution 4.0 International Licence which permits unrestricted use, distribution, and reproduction in any medium, provided the original work is properly cited. 


\section{An introduction to systems science}

This article begins by exploring the pandemic through a systems science approach. It then describes four converging systems and how they facilitated the emergence of the pandemic of COVID-19 which has disrupted the functioning of human civilization, at least temporarily. The systems considered are the earth systems and disruptions to biodiversity, the urbanocene and concentration of human populations, the virus and its infectivity and the human-goods system and hyper-connectivity.

The father of systems thinking, Ludwig von Bertalanffy, defined a system as "an entity that maintains its existence through the mutual interaction of its parts" (1968). It comprises interconnecting parts that change over time and affect the whole. These interactions are multiple, dynamic and have feedback loops which enable self-regulation. The collective outcomes of the system are significantly different features or characteristics that more than simply add to the contributions of the individual components of the system. Some of these systems are described as Complex Adaptive Systems (CAS) because they are "open" to environmental influences, demonstrate constant dynamic changes with nonlinear interactions between its components, have positive and negative feedback loops and constantly adapt and self-organize (Eidelson, 1997; Jayasinghe, 2011). CAS are increasingly used to understand natural sciences, social and biological systems and population health such as obesity.

The dynamics of any complex adaptive system is such that there are critical thresholds. These are abrupt, dramatic and non-linear, and move the system to a qualitatively different state. This process is called bifurcation or phases transition which is well described in physical systems, for example the transition from ice to water (Eidelson, 1977; von Bertalanffy, 1968). The parameters that push a CAS towards the critical phase are termed control parameters. Under situations well below the critical point small changes in the parameters have relatively proportionate effects on the system and there is general stability. However, as it approaches the critical phase, the system becomes less stable and begins to fluctuate more intensely and frequently, and a small change is capable of switching it to a different phase altogether.

\section{COVID-19 from the perspective of earth systems}

Earth Systems Science is a relatively new transdisciplinary field of study that attempts to understand the structure and functioning of the Earth as a CAS (Steffen et al., 2020). The interconnected earth system comprises several sub-systems, e.g. biosphere, atmosphere, geosphere, hydrosphere and cryosphere. The human-driven changes to the Earth, its land (i.e. part of geosphere), oceans (the hydrosphere), atmosphere and living organisms (i.e. the biosphere) impact and disrupt delicate balances and processes of nature at an unprecedented magnitude and speed (Steffen et al., 2020). Examples include the rapid pace of loss of global forest cover or the speed of extinction of species.

Earth Systems scientists have identified nine critical points termed planetary boundaries that are equivalent to the points of bifurcation of a CAS, after which the modes of operation may prove irreversible and less hospitable to humans and other forms 
of life (Steffen, 2015; IPBES, 2019). These could be considered as thresholds of nine of the earth's subsystems functioning at a global level that affect human survival: climate change (indicated by global warming etc.); biosphere integrity (assessed by biodiversity loss and extinctions); biogeochemical changes (i.e. anthropogenic phosphorous introduced to the oceans and removal of nitrogen from the atmosphere); ocean acidification; land use (of which conversion of land to grow crops is a key driver of loss in biodiversity); freshwater utilization; ozone layer in the stratosphere; overall particulate concentrations in the atmosphere; and chemical pollution and release of novel entities.

In the context of emerging infections, key roles are played by climate change and the loss of biodiversity (Keesing et al., 2010). The effects of climate change are mainly through global warming and the resurgence of disease-carrying vectors such as mosquitoes in otherwise cold climates. Examples include multiple epidemics of dengue, endemic dengue, and malaria in parts of Europe. Loss of biodiversity appears to be an even stronger trigger for emerging infections, especially at a more local level.

\section{Loss of biodiversity and infections}

The current rate of extinction of species is the highest ever and is accelerating. Of the vertebrate species alone, at least 680 species have become extinct since the 16th century. There are 8 million estimated animal and plant species, of which close to 1 million are threatened with extinction. The relationship between biodiversity and zoonotic infections continues to be controversial and complex.

Loss of biodiversity generally increases disease transmission and the prevalence of zoonotic diseases (Keesing et al., 2010). However, areas with high biodiversity can act as pools for new pathogens and add to the emergence of zoonotic infections from wildlife, i.e., an "amplification effect" (Jones et al., 2008). Increased diversity can also lead to decreased disease transmission and prevalence of the infection in the reservoir host, i.e., a "dilution effect" leading to lower rates of zoonotic infections (Luis et al., 2018). This paradoxical effect has been seen in studies on Sin Nombre hantavirus infections (SNV) and its main host, the deer mouse. SNV is transmitted directly by deer mice mainly to humans. It is also transmitted to other rodents though they are not important as reservoirs. Environments having a higher diversity of species led to a dilution effect of the main host (i.e., lower density) and a corresponding decrease in human hantavirus infections. However, when density of the host is taken into account it was found that a more diverse environment increased transmission to humans, an amplification effect (Luis et al., 2018).

Areas such as Wuhan city, which is believed to have been the epicenter of the COVID-19 pandemic, have experienced a rapid loss in vegetation and natural habitats due to the expansion of built-up areas and the indirect effects of cropland expansion. Remote sensing data suggest evidence of decrease in lake areas and the loss and fragmentation of wetlands due to urban expansion in and around Wuhan city (Gui et al., 2019). As a result, there is loss of habitats for wild species and a decrease in the biodiversity of the area (Ke et al., 2018). Such changes would have had complex effects on specific zoonotic species such as SARS-CoV-2. 
Another well-known factor in zoonosis is large-scale agriculture. It is estimated that since 1940, more than half the episodes of zoonosis were linked to expansion of agriculture and expansion of croplands. The evidence is even stronger in the case of emerging infections. In an analysis of 335 emerging infectious diseases between 1940 and 2004 it was found that the main cause was zoonosis $(60.3 \%)$ of which $71.8 \%$ originated in wildlife (e.g. Ebola virus). These origins were significantly correlated with social, environmental and ecological factors (Rohr et al., 2019).

\section{Virus spillover}

As a result of exploitation and loss of habitat and complex interactions, populations of wildlife species that have been reduced and domesticated species in the neighboring human habitats attract more zoonotic virus species (Johnson et al., 2020). Primates and bats are examples and have been the natural reservoirs of pathogens for several massive epidemics, such as apes in the case of HIV and bats in relation to SARS, Nipah and Ebola. Bats are tolerant to many viruses with zoonotic potential such as Ebola, rabies and coronaviruses, and seem to have a high frequency of harboring corona and other viruses. For these reasons bats were considered a special reservoir for zoonotic viruses, i.e., a "special reservoir hypothesis". However, recent studies indicate that this is not the case and that bats act as reservoirs in zoonosis in a manner expected of, and similar to, other mammals (Mollentze \& Streicker, 2020).

A factor that promotes bats as effective reservoirs for infection is that they themselves allow the virus to replicate yet remain asymptomatic, with minimal pathology. The proposed reason for this close relationship or co-existence is co-evolution of some of the viruses with species of bats. The virus is freely excreted in the saliva and the process of transmission could be through an intermediate such as horses and pigs or directly to humans as in the case of Nipah (Cui et al., 2007).

Spillover of the virus to humans is facilitated by the vector adapting to semi-urban environments of humans and increases in human-animal contacts such as hunting and wet markets. The exposure of infected animals to humans occurs through domestic animals, farm animals and wet markets. The latter is a feature in south east Asia and China where several species of wild animals are kept together for slaughter and sale. These markets and some of the restaurants promote bat-human and bat-animal interactions. This was demonstrated in the initial cases of SARS that occurred in a restaurant chef who had regular contact with bats and other wild animals as part of his job.

\section{The Virus System}

Bats (e.g. Rhinolophus affinis) are considered to be the natural hosts for a number of SARS-related coronaviruses. Malayan pangolins (Manis javanica) also have similar viruses. The spillover of viruses has little impact unless they are capable of infecting the human host. This capability and the species-jump from bats (or other hosts) to humans is dependent on the ability of the virus to invade human cells. Studies on the underlying molecular mechanisms indicate that the virus species in bats were able to enter human cells 
with mutations that produced a viral glycoprotein that could bind to the cell surface receptor human angiotensin converting enzyme 2 (ACE2). This was facilitated by rapid division and mutation rates, a characteristic of RNA viruses (Andersen et al., 2020; Plowright et al., 2015).

After the original mutation to SARS-CoV-2 in the animal host, it can follow one of two pathways: either natural selection in an animal host before zoonotic transfer or zoonotic transfer followed by natural selection in humans. The presence of minor self-contained epidemics or a low-grade pre-existing epidemic could account for the identification of SARS-CoV-2 in postmortem samples of persons who died on 6 February 2020, three weeks before the first case was reported from Washington (CDC COVID-19 Response Team, 2020).

While biodiversity was reducing, and mutant virus species were spilling over to humans through animal-human contact, two other parallel systems were also evolving at great speed. This related to concentrations of humans in urban areas and their physical connectivity through travel.

\section{The Urbanocene}

The 20th century has seen the growth of cities in an unprecedented manner. The density of the human population is a significant independent predictor of emerging infections.

Humans who were foragers a few thousands of years ago have progressively moved to larger villages, towns, cities and megacities, and had become, by 2007, largely urban dwellers with $50 \%$ of the species living in cities. This intense period of migration to cities, which in turn became the "crucible of civilization, the hubs of innovation, the engines of wealth creations and centers of power", is recognized as the urbanocene, developing as a sprout from the Anthropocene (West, 2017). The application of different models yields differential growth rates for urban areas. These growths include land use, population changes, mobility patterns and environmental changes (e.g., urban heat island formation) (Liu et al., 2019).

Since land reforms in 1987, China is undergoing a massive state-sponsored process of urbanization. Wuhan city with a population of 11.1 million in the Hubei Province of China has attracted the attention of researchers for several years. Initial studies used geographic information systems (GIS) and regression analyses to recognize determinants of spatial growth (Cheng \& Masser, 2003). Other techniques included remote sensing and network analyses. The city is undergoing an accelerated phase of urbanization. From 1990 to 2000 the urban population increased from $55.9 \%$ to $58.9 \%$ (annual growth rate of $0.3 \%$ ) and then from 2000 to 2015 to $70.6 \%$ (having an annual growth rate of $0.8 \%$ ). In contrast, from 1990 to 2000 urban land area grew from 263.2 ha to 295.8 ha (annual growth rate of $1.0 \%$ ) and accelerated from 2000 to 2015 having an annual growth rate that reached $6.0 \%$ (Wang et al., 2018).

The high density of urban populations results in close contact which will promote airborne spread of virus infections. 


\section{Physical Hyper-Connectivity}

\section{Mobility and global connectivity}

Mobility of humans has been a feature of civilization. These would have led to infections moving with migrating groups and traders. The spread of smallpox to Egypt in the 1st millennium $\mathrm{BC}$ was believed to be due to traders who arrived in caravans or by sea. In the 11th to 13th centuries the crusades and subsequent invasions led to the spread of infections in Spanish and Portuguese colonies (Thèves et al., 2016). In the pre-industrial period (14th to 18th century) the spread of plague followed major trade routes (Yue et al., 2017). In recent times, more rapid transport of humans across geographic locations has contributed to the rapid spread of diseases in several areas. This human connectivity has resulted in several such massive epidemics. It is believed that the influenza epidemic known as the Spanish Flu began in Europe, probably in British military camps around 1916 (Oxford et al., 2002). The infection subsequently spread to other military camps in France and was carried by migrant workers along rail routes to Spain, and across the Atlantic by US military personnel (Byerly, 2010; Trilla et al., 2008).

Excluding wars when large movements of troops occurred, travel during peacetime was limited to trade, work and recreation. Initial travel across long distances using motorized travel began with the construction of vehicles and trains. The latter began during the Industrial Revolution in the UK around 1825. Around the same time, large numbers of people began to use sea travel. However, the rapid and large-scale transport of people across continents effectively began with commercial air travel.

One facet of global connectivity is the mass of people who have now begun to move across cities, countries and continents. The other is the mobility of goods and mediums of transport, i.e. the movement of vehicles, ships and planes. Both these agents of connectivity have the capacity to transport infectious agents and organisms across thousands of miles.

This connectivity is brought about by the progressive increase in global air traffic passengers from around 2 billion in January 2010 to 3.5 billion by October 2019 (author's estimate from Figure 1 in Iacus et al., 2020). Though it is a small proportion of persons who repeatedly travel and account for these high figures, this is a massive volume of movement for a planet of about 7.8 billion persons (Iacus et al., 2020).

Within countries, the movement of people can be estimated by the proxy measure on the number of cars on the roads, which is close to a billion. This gives an opportunity for the rapid and wide spread of infections and for the generation of epidemics (Balcan et al., 2010; Colizza et al., 2006). The mobility patterns are quite complex and can be mathematically modelled (Zhao et al., 2015).

\section{Physical hyper-connectivity}

The term hyper-connectivity is often used in the field of information technology to indicate communication between persons, persons to machines and across machines. Machines and computers are linked to millions of other machines or computers (e.g. Internet of Things - IoTs, and people communicating with each other via the internet 
or mobile phones). These forms of massive networks with trillions of data transfers are unprecedented. In the physical sphere, I propose a novel concept of physical hyperconnectivity to indicate the connections between potential carriers of infections, animate or inanimate, and spanning from minute air pollution particles that carry viruses to humans who spread infections through travel to airplanes carrying malaria-carrying mosquitoes across continents.

A recent study reported that the global spread of diseases such as SARS is partly due to the air transportation network (Colizza et al., 2006; Pybus et al., 2015). The different modes of travel could have synergetic effects on spreading an infection, as seen with the Influenza A epidemic in China. The initial phase of spread was due to air and road travel, while in the later phases it was rail travel that facilitated the spread (Cai et al., 2019).

Connectivity of artefacts (in this instance defined as any object which requires human labour) when transporting goods and humans is another area that needs attention. Organisms surviving on the surfaces of such materials will act as fomites. The pathways taken by a product, from an airplane or a cargo container to a utility item, could easily traverse half the globe.

All these move around in parallel networks that span the whole globe, each item a potential carrier of contagion. What prevents it from being a major source of a global pandemic is that the virus or microorganism often fails to survive the harsh environments during travel or transport. Another source of potential wide spread of the virus could be in atmospheric dust particles. RNA has been detected in PM10 particles in outdoor samples in Italy (Setti et al., 2020), although its viability over distant travel is not known.

\section{The Perfect Storm in Complexity Science}

The hypothesis proposed in this article is that the four systems described above worked in parallel, converged, and led to interactions and synergies from which emerged the COVID-19 pandemic. The convergence of these different systems led to a "perfect storm": the emergence of the virus from loss of biodiversity in the earth systems; the ability of RNA viruses to mutate in the biological system; increased human-animal contact and concentrations of humans in urban areas facilitating spread of the virus; and finally, the networks of connectivity that promoted city-to-city spread.

CASs demonstrate three main patterns of behavior: periodic dynamics, chaotic dynamics, and random dynamics (criticality) (Katerndahl, 2013). It is likely that the four systems described in this article went through such fluctuations in their behavior and converged or demonstrated synergies at a critical point. From the perspective of the virus, the periodic dynamics pattern was when it was endemic in bats and other wild animals. There was a tight coupling of the virus' distribution as a system in the animals. This was through feedback loops (e.g. changes in the density of the host populations) where its current status of distribution was dependent on its previous state. Such patterns are considered predictable, show proportionate responses to interventions and are limited by restrictions of strong attractors (i.e. a status towards which a system evolves). This evolved to the subsequent pattern of chaotic dynamics where there is a temporal separation between 
actions and outcomes. This is illustrated by the virus having mini-epidemics among animals in urban areas (e.g. domestic animals, animals living in peri-urban areas and in animal markets) and among a few humans. This system is very sensitive to small changes and responds in a less predictable manner. However, there are attractors that limit the extent of the spread of the system. The final pattern was random dynamics (criticality) pattern. The virus spread had no attractors to limit its extent, and it rapidly cascaded across its usual environments to become a pandemic.

Similar fluctuations are seen in human mobility at macro and micro levels. At a macrolevel, seasonal movement of people based on tourism and holiday seasons often demonstrate periodic patterns. Within the city, there are clear patterns of human mobility based on those traveling to and away from a city during working days (Zhao et al., 2019). Changes to the earth systems probably follow seasons of the weather and crop cycles. An example is land denudation from initial deforestation which then leads to new crops that are harvested based on its cycles of growth. Wuhan had recently seen a massive increase in agricultural production and conducted the First Wuhan Agriculture Carnival in 2016 (General Office of Hubei Provincial People's Government, 2016). All these activities would lead to fluctuating levels of interactions between wild animals and humans.

\section{Conclusion}

Complexity science approaches are increasingly being applied to the natural sciences, population health, psychology and medicine (Jayasinghe, 2012, 2020). This article proposed a hypothesis based on complexity science to explain the COVID-19 pandemic. This hypothesis could be explored with quantitative data and developed into a mathematical model which may predict future epidemics and pandemics. The pandemic has had impacts on global pollution, sound levels, earth's vibrations and animal behaviours (Tollefson, 2020). The model can be refined using such data and can give scientists the tools to intervene and prevent future catastrophes. The article also introduces a novel concept of physical hyper-connectivity that could be explored further.

\section{References}

Andersen, K. G., Rambaut, A., Lipkin, W. I., Holmes, E. C., \& Garry, R. F. (2020). The proximal origin of SARS-CoV-2. Nature Medicine, 26, 450-452. https://doi.org/10.1038/s41591-0200820-9

Balcan, D., Gonçalves, B., Hu, H., Ramasco, J. J., Colizza, V., \& Vespignani, A. (2010). Modeling the spatial spread of infectious diseases: The global epidemic and mobility computational model. Journal of Computational Science, 1(3), 132-145. https://dx.doi.org/10.1016\%2Fj. jocs.2010.07.002

Byerly, C. R. (2010). The U.S. military and the influenza pandemic of 1918-1919. Public Health Reports, 125 Suppl 3, 82-91. 
Cai, J., Xu, B., Chan, K. K. Y., Zhang, X., Zhang, B., Chen, Z., \& Xu, B. (2019). Roles of different transport modes in the spatial spread of the 2009 Influenza A(H1N1) pandemic in mainland China. International Journal of Environmental Research and Public Health, 16(2), Article 222. https://doi.org/10.3390/ijerph16020222

Center for Disease Control, COVID-19 Response Team. (2020). Evidence for limited early spread of COVID-19 within the United States, January - February 2020. Morbidity and Mortality Weekly Report, 69(22), 680-684. http://dx.doi.org/10.15585/mmwr.mm6922e1external icon

Cheng, J., \& Masser, I. (2003). Urban growth pattern modeling: A case study of Wuhan city, PR China. Landscape and Urban Planning, 62(4), 199-217. https://doi.org/10.1016/s01692046(02)00150-0

Colizza, V., Barrat, A., Barthélemy, M., \& Vespignani, A. (2006). The role of the airline transportation network in the prediction and predictability of global epidemics. Proceedings of the National Academy of Sciences of the United States of America, 103(7), 2015-2020. https://doi. org/10.1073/pnas.0510525103

Cui, J., Han, N., Streicker, D., Li, G., Tang, X., Shi, Z., Hu, Z., Zhao, G., Fontanet, A., Guan, Y., Wang, L., Jones, G., Field, H. E., Daszak, P., \& Zhang, S. (2007). Evolutionary relationships between bat coronaviruses and their hosts. Emerging Infectious Diseases, 13(10), 1526-1532. https://doi.org/10.3201/eid1310.070448

Eidelson, R. J. (1997). Complex adaptive systems in the behavioral and social sciences. Review of General Psychology, 1(1), 42-71. https://doi.org/10.1037/1089.2680.1.1.42

General Office of Hubei Provincial People's Government. (2016, March). Over 300 kinds of crops appear in Wuhan Agriculture Carnival. Retrieved August 29, 2020, from http://en.hubei.gov. cn/news/newslist/201603/t20160329_811390.shtml

Gui, X., Wang, L., Yao, R., Yu, D., \& Li, C. (2019). Investigating the urbanization process and its impact on vegetation change and urban heat island in Wuhan, China. Environmental Science and Pollution Research, 26(30), 30808-30825. https://doi.org/10.1007/s11356-019-06273-w

Iacus, S. M., Natale, F., Santamaria, C., Spyratos, S., \& Vespe, M. (2020; published online ahead of print, 2020 May 6). Estimating and projecting air passenger traffic during the COVID-19 coronavirus outbreak and its socio-economic impact. Safety Science, 129, Article 104791. https://doi.org/10.1016/j.ssci.2020.10479

Intergovernmental Science-Policy Platform on Biodiversity and Ecosystem Services (IPBES). (2019). Summary for Policymakers of the Global Assessment Report on Biodiversity and Ecosystem Services. S. Díaz, J. Settele, E. S. Brondízio, H. T. Ngo, M. Guèze, J. Agard, A. Arneth, P. Balvanera, K. A. Brauman, S. H. M. Butchart, K. M. A. Chan, L. A. Garibaldi, K. Ichii, J. Liu, S. M. Subramanian, G. F. Midgley, P. Miloslavich, Z. Molnár, D. Obura ... C. N. Zayas (Eds.). IPBES Secretariat. https://ipbes.net/global-assessment

Jayasinghe, S. (2011). Conceptualising population health: From mechanistic thinking to complexity science. Emerging Themes in Epidemiology, 8(1), Article 2. https://doi.org/10.1186/1742$7622-8-2$

Jayasinghe, S. (2012). Complexity science to conceptualize health and disease: is it relevant to clinical medicine? Mayo Clinic Proceedings, 87(4), 314-319. https://doi.org/10.1016/j. mayocp.2011.11.018 
Jayasinghe, S. (2020, April 14; published online ahead of print). Conceptualizing mind wandering using a systems approach: A preliminary exploration. Integrative Psychological and Behavioral Science. https://doi.org/10.1007/s12124-020-09527-2

Johnson, C. K., Hitchens, P. L., Pandit, P. S., Rushmore, J., Evans, T. S., Young, C. C. W., \& Doyle, M. M. (2020). Global shifts in mammalian population trends reveal key predictors of virus spillover risk. Proceedings of the Royal Society B: Biological Sciences, 287, Article 20192736. http://dx.doi.org/10.1098/rspb.2019.2736

Jones, K. E., Patel, N. G., Levy, M. A., Storeygard, A., Balk, D., Gittleman, J. L., \& Daszak, P. (2008). Global trends in emerging infectious diseases. Nature, 451, 990-993. https://doi.org/10.1038/ nature06

Katerndahl, D. A. (2013). Understanding intimate partner violence through its dynamics. In J. P. Sturmberg \& C. M. Martin (Eds.), Handbook of systems and complexity in health (pp. 335-354). Springer Science and Business Media.

Ke, X., van Vliet, J., Zhou, T., Verburg, P. H., Zheng, W., \& Liu, X. (2018). Direct and indirect loss of natural habitat due to built-up area expansion: A model-based analysis for the city of Wuhan, China. Land Use Policy, 74, 231-239. https://doi.org/10.1016/j.landusepol.2017.12.048

Keesing, F., Belden, L. K., Daszak, P., Dobson, A., Harvell, C. D., Holt, R.D., Hudson, P., Jolles, A., Jones, K. E., Mitchell, C. E., Myers, S. S., Bogich, T. \& Ostfel, R. S. (2010). Impacts of biodiversity on the emergence and transmission of infectious diseases. Nature, 468, 647-652. https://doi.org/10.1038/nature09575

Liu Y., Li L., Chen L., Cheng L., Zhou X., Cui Y., Li, H., \& Liu, W. (2019). Urban growth simulation in different scenarios using the SLEUTH model: A case study of Hefei, East China. PLoS ONE, 14(11), e0224998. https://doi.org/10.1371/journal. pone.0224998

Luis, A. D., Kuenzi A. J., \& Mills. J. N. (2018). Species diversity concurrently dilutes and amplifies transmission in a zoonotic host - pathogen system through competing mechanisms. Proceedings of the National Academy of Sciences, 115(31), 7979-7984. https://doi.org/10.1073/ pnas. 1807106115

Mollentze, N., \& Streicker, D. G. (2020). Viral zoonotic risk is homogenous among taxonomic orders of mammalian and avian reservoir hosts. Proceedings of the National Academy of Sciences, 117(17), 9423-9430. https://dio.org/10.1073/pnas.1919176117

Oxford, J. S., Sefton, A., Jackson, R., Innes, W., Daniels, R. S., \& Johnson, N. P. A. S. (2002). World War I may have allowed the emergence of "Spanish" influenza. The Lancet: Infectious Diseases, 2(2), 111-114. https://doi.org/10.1016/s1473-3099(02)00185-8

Plowright, R. K., Eby, P., Hudson, P. J., Smith, I. L., Westcott, D., Bryden, W. L., Middleton, D., Reid, P. A., McFarlane, R. A., Martin, G., Tabor, G. M., Skerratt, L. F., Anderson, D. L., Crameri, G., Quammen, D., Jordan, D., Freeman, P., Wang, L., Epstein, J. H., ... McCallum, H. (2015). Ecological dynamics of emerging bat virus spillover. Proceedings of the Royal Society B: Biological Sciences, 282(1798), Article 20142124. http://dx.doi.org/10.1098/rspb.2014.2124

Pybus, O. G., Tatem, A. J., \& Lemey, P. (2015). Virus evolution and transmission in an ever more connected world. Proceedings of the Royal Society B: Biological Sciences, 282(1821), Article 20142878. http://dx.doi.org/10.1098/rspb.2014.2878 
Rohr, J. R., Barrett, C. B., Civitello, D. J., Craft, M. E., Delius, B., DeLeo, G. A., Hudson, P. J., Jouanard, N., Nguyen, K. H., Ostfeld, R. S., Remais J. V., Riveau, G., Sokolow, S. H., \& Tilman, D. (2019). Emerging human infectious diseases and the links to global food production. Nature Sustainability, 2(6), 445-456. https://doi.org/10.1038/s41893-019-0293-3

Setti, L., Passarini, F., De Gennaro, G., Barbieri, P., Pallavicini, A., Ruscio, M., Piscitelli, P., Colao, A., \& Miani, A. (2020). Searching for SARS-COV-2 on particulate matter: A possible early indicator of COVID-19 epidemic recurrence. International Journal of Environmental Research and Public Health, 17(9), Article 2986. https://doi.org/10.3390/ijerph17092986

Steffen, W., Richardson, K., Rockström, J., Cornell, S. E., Fetzer, I., Bennett, E. M., Biggs, R., Carpenter, S. R., de Vries, W., de Witt, C. A., Folke, C., Gerten, D., Heinke, J., Mace, G. M., Persson, L. M., Ramanathan, V., Reyers, B. \& Sörlin, S. (2015). Planetary boundaries: Guiding human development on a changing planet. Science, 347(6223), Article 1259855. https://dx.dio. org/0.1126/science. 1259855

Steffen, W., Richardson, K., Rockström, J., Schellnhuber, H. J., Dube, O. P., Dutreuil, S., Lenton, T. M., \& Lubchenco, J. (2020). The emergence and evolution of earth system science. Nature Reviews Earth and Environment, 1, 54-63. https://doi.org/10.1038/s43017-019-0005-6

Thèves, C., Crubézy, E., \& Biagini, P. (2016). History of smallpox and its spread in human populations. Microbiol Spectrum, 4(4), PoH-0004-2014. https://doi.org/10.1128/microbiolspec.PoH-00042014

Tollefson, J. (2020, May 20). How the coronavirus pandemic slashed carbon emissions - in five graphs. Nature. https://www.nature.com/articles/d41586-020-01497-0

Trilla, A., Trilla, G., \& Daer, C. (2008). The 1918 "Spanish Flu” in Spain. Clinical Infectious Diseases, 47(5), 668-73.

von Bertalanffy, L. (1968). General system theory: Foundations, development, applications. Braziller.

Wang, Y., Li, X., Li, J., Huang, Z., \& Xiao, R. (2018). Impact of rapid urbanization on vulnerability of land system from complex networks view: A methodological approach. Complexity, 2018, Article 8561675. https://doi.org/10.1155/2018/8561675

West, G. (2017). Scale: The universal laws of growth, innovation, sustainability, and the pace of life in organisms, cities, economies, and companies. Penguin Press.

Yue, R. P. H., Lee, H. F., \& Wu, C. Y. H. (2017). Trade routes and plague transmission in pre-industrial Europe. Scientific Reports, 7, Article 12973. https://doi.org/10.1038/s41598-017-13481-2

Zhao, K., Musolesi, M., Hui, P., Rao, W., \& Tarkoma. S. (2015). Explaining the power-law distribution of human mobility through transportation modality decomposition. Scientific Reports, 5, Article 9136. https://doi.org/10.1038/srep09136

Zhao, Y., Zhu, X., Guo, W., She, B., Yue, H., \& Li, M. (2019). Exploring the weekly travel patterns of private vehicles using automatic vehicle identification data: A case study of Wuhan, China. Sustainability, 11, Article 6152. https://doi.org/10.3390/su11216152 